\title{
Systematically understanding faculty needs

\author{
Using Zotero in liaison work
}

I n 2012, the Baylor University Central Libraries underwent a reorganization, which created a department of Liaison Services (LS) out of the former Reference and Library Instruction (RLI) department. While the RLI librarians had always functioned to a certain degree as liaisons to their assigned departments, this reorganization not only officially changed our name (from "consultant" to "liaison") but also helped to sharpen our focus on supporting faculty and graduate student research and teaching. ${ }^{1}$ We hoped that our instructional efforts among undergraduates would become more purposeful when they flowed organically out of working with the faculty more closely.

One major change in duties meant that liaison service librarians (LSL) no longer staffed the reference desk. The time the LSL's gained from this change allowed us to focus on liaison activities in our assigned departments and to be free to take appointments with our departments' faculty, students, and any referrals from the desk.

Among the goals of the Central Libraries is to "provide an infrastructure that most effectively supports the academic mission of a research university"; ${ }^{2}$ two outcomes of this goal are a) to build a greater understanding of researcher needs, aligning initiatives with the culture of academic departments served by liaison libraries and b) to build capacity to support faculty, graduate student and undergraduate research. The LS department was formed and duties were assigned that allowed the LSLs to learn the departmental cultures and research needs of their patrons.

\section{My liaison departments}

When I started working at the Baylor Central Libraries, I was assigned two academic departments-Modern Languages and Cultures (MLC) and Family and Consumer Sciences (FCS). A few years later, I was assigned two more-Journalism, Public Relations, and New Media (JPRNM) and Communication. My liaison departments are large, complex departments comprised of many varied divisions and programs. MLC includes 4 divisions, teaches 11 languages, and offers 5 majors, 8 minors, and a master's degree.

The programs offered by FCS fall under the disciplinary banners of Fine Arts (Interior Design, Apparel Design), Social Science (General Family and Consumer Science, Child and Family Studies), Science (Nutrition Sciences), and Business (Apparel Merchandising). Communication is made up of the divisions of Communication Studies and Film and Digital Media (which split into two separate departments during summer 2015). The Journalism department changed its name a few years ago to reflect the program offerings in Public Relations and New Media that had been added.

Ellen Hampton Filgo is e-learning librarian at Baylor University, ellen_filgo@baylor.edu

๑ 2016 Ellen Hampton Filgo 
The faculty in my liaison departments have very different research agendas, resource needs, and desires for library instruction. One of the first LSL charges after the department was formed was to create a formal liaison plan for each assigned department. In order to do that, I knew that I needed to have an organized approach to better understand my faculty's research needs. Until then, I had only a haphazard approach to knowing about the research of my departmental faculty. That knowledge came from department website profiles (some long and detailed, other quite bare-bones), or when faculty submitted "Suggest a Purchase" items (which may or may not be related to their research agendas), or through my contact with the faculty who asked for library research instruction for their classes.

I did have a better understanding of the newer faculty because of the incoming faculty orientation that the library hosts each fall. This orientation provides a built-in mechanism for meeting the new faculty, and during this time we try to orient them to library resources and services, talk about their research agendas, and receive any urgent resource purchasing suggestions. However,

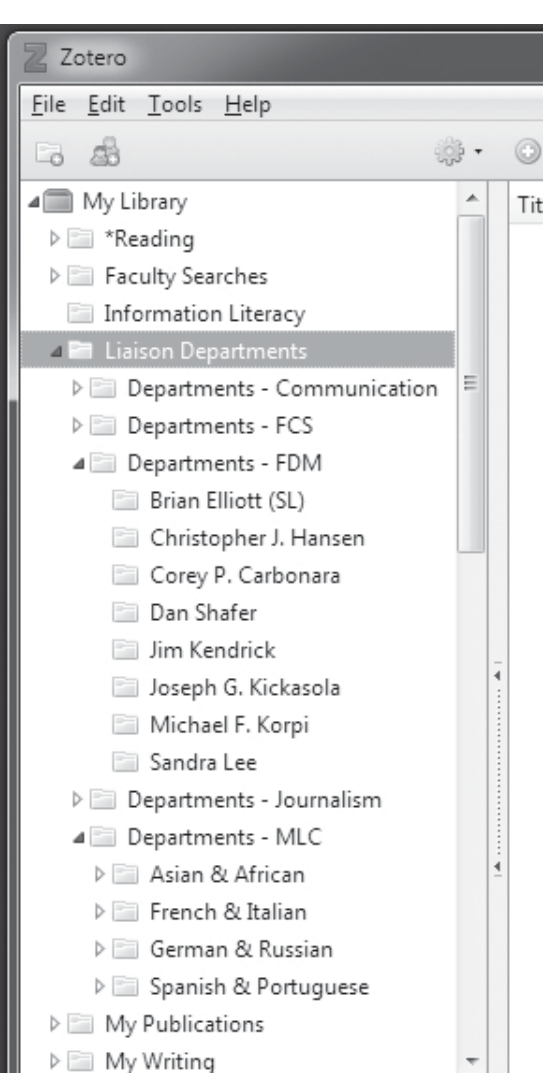

Folder structure. View this article online for more detailed images. with LS's renewed focus on understanding our faculty's needs, I needed a systematic way to be able to see my departments' research output at a broad glance, as well as be able to focus on individual faculty research agendas.
In order to do this, I decided to use the Zotero Citation Management program. I am familiar with Zotero, as I have been the Baylor Libraries' main Zotero trainer and evangelist since 2009, after attending a formal Zotero "train the trainers" workshop. While familiarity with the program was the main factor is choosing Zotero, I also liked the uncomplicated way in which materials can be added to the Zotero library, and the ease of organizing those materials.

\section{Getting started}

In Zotero, I set up collections for each of my departments, then subcollections for each division or program. In each of those subcollections, I created a folder for each faculty member in that area. For the faculty members who are not on tenure track, and therefore do not have an expectation of publishing, I put an (L)Lecturer or (SL)-Senior Lecturer after their name to remind me. Many of the lecturers in my departments do publish-and in some cases they are working on dissertations themselves-so I wanted to include them alongside the tenure-track faculty. To download my faculty publications, I used the following resources:

- BearCat (our local OPAC) and WorldCat;

- Subject databases (MLA, Communication and Mass Media Complete, etc.);

- Proquest Dissertations and Theses;

- Google Scholar; and

- OneSearch (our locally branded Summon discovery interface). 
I also crosschecked what I discovered in the databases with the faculty CVs published on departmental websites. If something was listed there that I hadn't already found, I would search for it in either Google Scholar or OneSearch, or, failing that, add it in manually.

While many of my departments have traditional publishing patterns-books, articles, reviews, and conference papers-I have a few areas where publications take on different forms, and Zotero is able to from database subject headings that Zotero downloads as tags. I often added to these notes as I learned more about specific interests about the faculty I met. I also added web page items for a faculty member's professional website, blog, Google Scholar citations page, ORCID profile page, or any other web page of scholarly significance.

\section{Keeping publications updated}

The initial search to download the faculty publications took the most time. As new

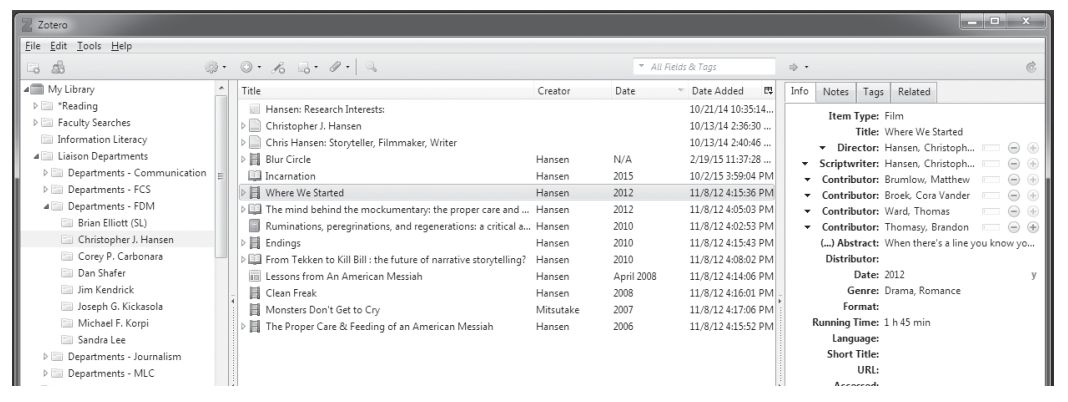

Nontraditional formats.

handle them with ease. Because Zotero works within the Internet browser, it easily downloads information that is beyond the traditional publishing forms. For example, many Film and Digital Media faculty are engaged in creative pursuits. One faculty member regularly publishes film reviews on a website, which can be added with the "save page to Zotero" menu item. Another faculty member is an accomplished filmmaker, and I was able to download his film information from IMDb.com, for which there is a Zotero download icon. In the JPRNM department, I work with several faculty members who have had careers as journalists before coming to academia. Zotero also works with many major newspaper websites.

In addition to downloading faculty publications, I also added more items to each faculty collection. The first is a standalone note that lists each faculty member's research interests, which also serves as their profile. These I gathered from either departmental websites or extrapolated faculty arrive, I go back to the project and every few months update the collections with new publications. I keep up with new publications in a variety of ways. First, the Marketing and Communications division at Baylor publishes a quarterly news bulletin that always lists new grants, publications, and presentations that are self-submitted by the university faculty. Several departments also publish their own list of new faculty publications, either on their websites or in their departmental newsletters. These lists have become regular sources of updates. From my contact with some faculty on social media I also become apprised of new or upcoming publications. For some of the more prolific faculty, I have also set up Google Scholar alerts.

\section{Getting a new department}

During spring 2015, one of our longstanding liaison librarians announced her retirement. Her liaison departments were reassigned on an interim basis to the other liaison librarians. I was assigned the de- 
partment of Curriculum and Instruction within the School of Education. I decided to add this department to my Zotero library of faculty publications because I was curious to see how quickly I could come up to speed on this department's scholarly output. I had already been working with my current departments for four to five years before downloading their research into Zotero, so I did have some previous, though haphazard, knowledge about their scholarship. This new department was a blank slate. It did not take me very long to download this new department's research output and thereby gain a good understanding of the scope of research being done and by whom. Interestingly, I was faculty's research and teaching interests, ${ }^{5}$ and then through this knowledge, being able to customize and personalize your interactions and engagement. ${ }^{6}$ Having an easily accessible and comprehensive repository of my liaison departments' publication history through Zotero has become the key to understanding them.

When brief interactions-departmental hallway conversations, standing in line at the library's coffee shop, or casual posts on social media-can mean so much in developing meaningful liaison relationships, ${ }^{7}$ knowing each faculty member's interests this way means that I'm not caught ill-prepared and can be proactive during those quick conversations.

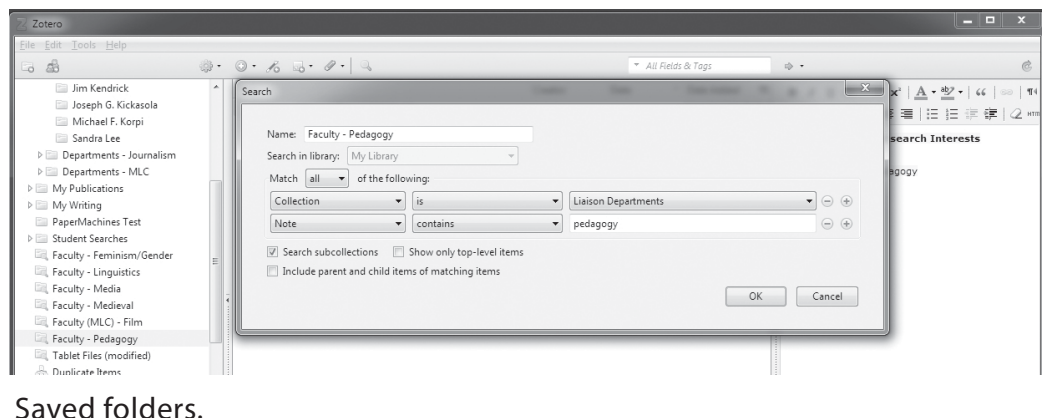

Saved folders.

able to note the high level of collaboration among this department's faculty.

\section{Zotero and liaison work}

While there are many models for what a library's liaison program might look like, there are some foundational activities. The Iowa Framework for Liaisons/Subject Librarians notes that liaison librarians should "analyze trends in departmental teaching and research programs, stay abreast of scholarship in the disciplines themselves, and use this knowledge to respond to departmental needs." 3 The ARL report "New Roles for New Times" describes a model of liaison librarianship that is outward-focused, engaging creatively with the users, and "participat[ing] in the entire lifecycle of the research, teaching, and learning process." ${ }^{\prime 4}$ Across the library literature, there is an emphasis on the importance of knowing your liaison department's curricula and the
Even though collection development has become a smaller part of my liaison work, Zotero helps me make more informed selections of library materials, and I am able to promote those resources and other library services in a tailored way, rather than just as an email blast to an entire department. I can also easily make connections between faculty across my departments by using Zotero's search feature. I have several saved search folders on interdisciplinary topics (gender, media, film, pedagogy, etc.) that automatically collect all of the profiles of the faculty interested in those topics. In this scholarly era, where interdisciplinary research is prized, I want the library to be a place where those connections can be both created and fostered.

In the spring and summer of 2015, the libraries began a campaign to promote the use of ORCID scholarly profiles across campus. ${ }^{8}$ As a part of that campaign, the LSLs offered to populate the profiles of the faculty in their departments 
with their scholarly output. Because I already had collected my faculty's research into Zotero folders, it was very easy for me to complete this task efficiently by using Zotero's BibTeX export and ORCID's BibTeX import features.

Zotero can be such a benefit to scholars as they collect, organize, and cite materials in their own research because of its user-friendly interface and seamless integration with the tools scholars use. Similarly, it has been a huge benefit to me as I have settled into my role as a liaison librarian, helping me easily understand, and therefore engage with, the faculty in my liaison departments.

\section{Notes}

1. Jeffrey Steely, "Central Libraries Reorganization," Baylor Central Libraries, April 15, 2013, http://blogs.baylor.edu/centrallibraries/2013/04/15/central-libraries-reorganization/.

2. Baylor University Libraries, "Mission Statement," accessed September 20, 2015, http://www.baylor.edu/lib/index. php?id=98514.

3. Edward Shreeves et al., "Iowa Framework for Liaisons/Subject Librarians," University of Iowa Libraries Staff Publications, April 2, 2009, http://ir.uiowa.edu/lib_pubs/120.

4. Janice Jaguszewski and Karen Williams, "New Roles for New Times: Transforming Liaison Roles in Research Libraries," 2013, 4, http://conservancy.umn.edu/ handle/11299/169867.
5. Richard A. Stoddart et al., "Going Boldly beyond the Reference Desk: Practical Advice and Learning Plans for New Reference Librarians Performing Liaison Work," The Journal of Academic Librarianship 32, no. 4 (July 2006): 419-27, doi:10.1016/j.acalib.2006.03.009; Tom Glynn and Connie Wu, "New Roles and Opportunities for Academic Library Liaisons: A Survey and Recommendations," Reference Services Review 31, no. 2 (June 1, 2003): 122-28, doi:10.1108/00907320310476594.

6. James Thull and Mary Anne Hansen, "Academic Library Liaison Programs in US Libraries: Methods and Benefits," New Library World 110, no. 11/12 (November 20, 2009): 529-40, doi:10.1108/03074800911007541; Melissa A. Kozel-Gains and Richard A. Stoddart, "Experiments and Experiences in Liaison Activities: Lessons from New Librarians in Integrating Technology, Face-to-Face, and Follow-Up," Collection Management 34, no. 2 (April 1, 2009): 130-42, doi:10.1080/01462670902729150.

7. Ellen Hampton Filgo and Sha Towers, "The 'Hangout Factor' in Library Liaison Work: An Exploration" (poster, Cross-Timbers Library Collaborative Conference, Commerce, TX, August 7,2015 ).

8. Christina Chan-Park and Billie PetersonLugo, "The Sweet Smell (and Taste) of Success: Incentivizing ORCID iD Sign-Ups Among Faculty and Graduate Students," in 2015 Texas Conference on Digital Libraries, 2015, https:// conferences.tdl.org/tcdl/index.php/TCDL/ TCDL2015/paper/view/852. n

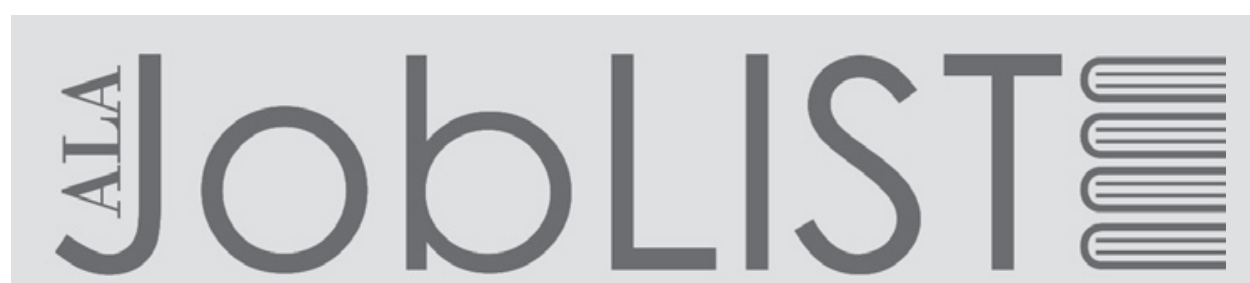

The \#1 source for jobs in Library and Information Science and Technology

JOB SEEKERS

Search and sort hundreds

of job ads by position type,

employer, location, and more

\section{EMPLOYERS}

Strengthen your candidate pool-

ALA reaches the most engaged

professionals and students

\section{joblist.ala.org}

